\title{
Identification of focal ARDS using ventilatory ratio
}

\author{
Kay Choong See ${ }^{1,2^{*}} \mathbb{0}$, Melanie Torres Estaras ${ }^{3}$ and Juvel Mabao Taculod ${ }^{3}$
}

Keywords: Diagnosis, Lung, Respiratory distress syndrome, Adult, Ultrasonography

\section{Dear Editor}

Acute respiratory distress syndrome (ARDS) patients with disease predominantly in the posterobasal lung regions (i.e., focal ARDS) benefited from prone positioning, while patients with diffuse (non-focal) ARDS benefited from recruitment maneuvers and high positive end-expiratory pressures, provided focal ARDS was correctly classified [1]. Classification of ARDS morphology using imaging is however challenging, as computed tomography is resource intensive, and lung ultrasound is operator dependent.

Alternative methods for focal ARDS identification are therefore needed. Our prior study using partial pressure of arterial oxygen divided by fraction of inspired oxygen (P/F ratio) did not allow the identification of focal ARDS morphology [2], suggesting that the degree of oxygenation impairment is related to the extent rather than the distribution of lung involvement. Another physiological parameter-the ventilatory ratio (VR), as an estimate of dead space fraction [3]-holds promise. Compared to patients with diffuse ARDS, patients with focal ARDS had lower physiological dead space, which was computed according to the Enghoff modification of Bohr's equation [4]. We therefore hypothesized that VR could help to identify focal ARDS.

\footnotetext{
*Correspondence: kay_choong_see@nuhs.edu.sg

${ }^{1}$ Division of Respiratory and Critical Care Medicine, Department of Medicine, National University Hospital, 1 E Kent Ridge Road, NUHS

Tower Block Level 10, Singapore 119228, Singapore

Dr. See has received honoraria and travel support from Medtronic and GE Healthcare. This work was performed at the National University Hospital, Singapore

Full list of author information is available at the end of the article
}

Patients were included if they had ARDS fulfilling the Berlin Definition and received invasive mechanical ventilation. On admission, trained respiratory therapists performed 12-point lung ultrasound using a 2-4 $\mathrm{MHz}$ phased array transducer and semi-quantitatively scored each region [5]. We identified focal ARDS on lung ultrasound, if the consolidated regions were only present in the posterobasal regions and absent in the anteroapical regions $[1,2]$. VR, a dimensionless variable, was computed as (minute ventilation $\times$ partial pressure of arterial carbon dioxide)/(predicted body weight $\times 3750$ ) [3].

The association of focal ARDS with VR was analyzed assuming a nonlinear relationship. A logistic regression model was fitted using a restricted cubic spline with four knots and taking the VR of the first knot as the reference level. Should the spline suggest a VR threshold for prediction of focal ARDS, we proceeded to elucidate this threshold by performing binary logistic regression using focal ARDS as the independent variable and VR threshold as the dependent variable, with the latter tested in 0.1 intervals.

A total of 152 patients were studied (age $63.3 \pm 14.1$ years; 53 (34.9\%) female; mean $\mathrm{P} / \mathrm{F}$ ratio $148 \pm 71 \mathrm{mmHg}$; mean VR $2.18 \pm 1.19$; ICU mortality 16.5\%; hospital mortality 33.6\%). Sixteen (10.3\%) had focal ARDS. Admission diagnoses were as follows: pneumonia (61 patients; 40.1\%), non-pneumonia sepsis (19; $12.5 \%)$, chronic obstructive pulmonary disease $(9 ; 5.9 \%)$, acute myocardial infarction (3; $2.0 \%)$, stroke (12; 7.9\%), other diagnoses such as massive hemoptysis, pulmonary vasculitis and pneumonitis (48; 32.6\%). Median lung ultrasound scores (interquartile range) were as follows:

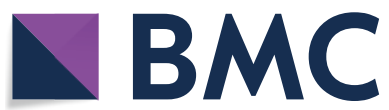

(c) The Author(s) 2021. Open Access This article is licensed under a Creative Commons Attribution 4.0 International License, which permits use, sharing, adaptation, distribution and reproduction in any medium or format, as long as you give appropriate credit to the original author(s) and the source, provide a link to the Creative Commons licence, and indicate if changes were made. The images or other third party material in this article are included in the article's Creative Commons licence, unless indicated otherwise in a credit line to the material. If material is not included in the article's Creative Commons licence and your intended use is not permitted by statutory regulation or exceeds the permitted use, you will need to obtain permission directly from the copyright holder. To view a copy of this licence, visit http://creativecommons.org/licenses/by/4.0/. The Creative Commons Public Domain Dedication waiver (http://creativeco mmons.org/publicdomain/zero/1.0/) applies to the data made available in this article, unless otherwise stated in a credit line to the data. 


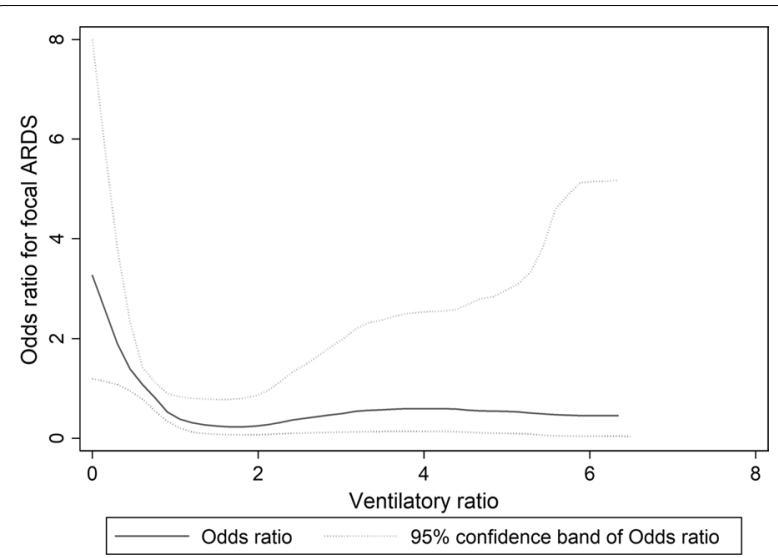

Fig. 1 Association of odds ratio for focal ARDS with ventilatory ratio, using a restricted cubic spline with four knots

right posterobasal $3(0-6)$, left posterobasal $2.5(0-5)$, right anteroapical $0(0-3)$, left anteroapical $2(0-3)$.

Spline analysis suggested a threshold effect (Fig. 1). A VR of $<1.2$ was associated with focal ARDS (odds ratio 3.41, 95\% confidence interval 1.05-11.1, $P=0.041$ ), with sensitivity $31.3 \%$, specificity $88.3 \%$, positive predictive value $23.8 \%$, and negative predictive value $91.6 \%$. As such, VR $>1.2$ could help exclude focal ARDS and aid personalized ARDS management, though our preliminary findings require external validation.

\section{Abbreviations}

ARDS: Acute respiratory distress syndrome; $\mathrm{P} / \mathrm{F}$ ratio: Ratio of partial pressure of arterial oxygen divided by fraction of inspired oxygen; VR: Ventilatory ratio.

\section{Acknowledgements}

The authors would like to thank the physicians, nurses and respiratory therapists who have cared for our patients.

\section{Authors' contributions}

KCS contributed to study concept, design, drafting of manuscript. All authors contributed to study conduct, data analysis and interpretation, critical revision of the manuscript for important intellectual content. All authors had full access to all of the data in the study and take responsibility for the integrity of the data and the accuracy of the data analysis.

\section{Funding}

No funding was required for this study.

\section{Availability of data and materials}

The data that support the findings of this study are available from the corresponding author, $\mathrm{KCS}$, upon reasonable request.

\section{Declarations}

\section{Ethics approval and consent to participate}

Our Ethics Review Board (National Healthcare Group Domain-Specific Review Board) approved the study (approval number DSRB B/2013/00132). As the study is a retrospective observational one, the need for patient consent was waived.

\section{Consent for publication}

Not applicable.

\section{Competing interests}

KCS has received honoraria and travel support from Medtronic and GE Healthcare. MTE and JMT have no conflicts of interest to declare.

\section{Author details}

${ }^{1}$ Division of Respiratory and Critical Care Medicine, Department of Medicine, National University Hospital, 1 E Kent Ridge Road, NUHS Tower Block Level 10, Singapore 119228, Singapore. ${ }^{2}$ Department of Medicine, Yong Loo Lin School of Medicine, National University of Singapore, Singapore, Singapore. ${ }^{3}$ Division of Critical Care - Respiratory Therapy, National University Hospital, Singapore, Singapore.

Received: 13 October 2021 Accepted: 14 October 2021

Published online: 24 October 2021

\section{References}

1. Constantin JM, Jabaudon M, Lefrant JY, Jaber S, Quenot JP, Langeron O, Ferrandiere M, Grelon F, Seguin P, Ichai C, et al. Personalised mechanical ventilation tailored to lung morphology versus low positive endexpiratory pressure for patients with acute respiratory distress syndrome in France (the LIVE study): a multicentre, single-blind, randomised controlled trial. Lancet Respir Med. 2019;7(10):870-80.

2. See KC, Sahagun J, Taculod J. Identification of focal ARDS using PF ratio: a cross-sectional study. Crit Care. 2020:24(1):471.

3. Sinha P, Calfee CS, Beitler JR, Soni N, Ho K, Matthay MA, Kallet RH. Physiologic analysis and clinical performance of the ventilatory ratio in acute respiratory distress syndrome. Am J Respir Crit Care Med. 2019:199(3):333-41.

4. Coppola S, Pozzi T, Gurgitano M, Liguori A, Duka E, Bichi F, Ciabattoni A, Chiumello D. Radiological pattern in ARDS patients: partitioned respiratory mechanics, gas exchange and lung recruitability. Ann Intensive Care. 2021;11(1):78.

5. See KC, Ong V, Wong SH, Leanda R, Santos J, Taculod J, Phua J, Teoh CM. Lung ultrasound training: curriculum implementation and learning trajectory among respiratory therapists. Intensive Care Med. 2016;42(1):63-71.

\section{Publisher's Note}

Springer Nature remains neutral with regard to jurisdictional claims in published maps and institutional affiliations. 